\title{
论文
}

\section{基于二级结构 $\mathrm{TiO}_{2}$ 纳米晶光阳极的高效染料敏化 太阳能电池}

\author{
兰章*，吴季怀*，林建明，黄妙良
}

环境友好功能材料教育部工程中心; 福建省高校功能材料重点实验室; 华侨大学材料物理化学研究所, 厦门 361021

*通讯作者, E-mail: lanzhang@ @qu.edu.cn; jhwu@hqu.edu.cn

收稿日期: 2013-10-05; 接受日期: 2013-11-25; 网络版发表日期: 2014-04-18

doi: 10.1007/s11426-013-5052-0

\begin{abstract}
摘要本文报道了一种新型的二级结构 $\mathrm{TiO}_{2}$ 纳米晶 $\left(\right.$ nano- $\left.\mathrm{TiO}_{2}\right)$ 光阳极的简单制备方 法及其在高效染料敏化太阳能电池中的应用。通过添加适量 $\mathrm{TiCl}_{4}$ 异丙醇溶液到传统 nano- $\mathrm{TiO}_{2}$ 浆料中, 可生成微米级 nano- $\mathrm{TiO}_{2}$ 聚集体. 该二级结构能有效提高光阳极光谱 吸收和散射性能及电子传输和收集效率. 基于这种结构光阳极的染料敏化太阳能电池光 电性能有显著提高. 在光阳极中将 $6 \mu \mathrm{m}$ 厚传统 nano- $\mathrm{TiO}_{2}$ 膜用相同厚度 nano- $\mathrm{TiO}_{2}$ 聚集 体替换, 电池光电转换效率由 $5.03 \%$ 提高到 $7.30 \%$. 进一步增加 nano- $\mathrm{TiO}_{2}$ 聚集体的厚度 能制备出更高光电转换效率的电池.
\end{abstract}

关键词

染料敏化太阳能电池 光阳极

二级结构

四氯化钛添加剂

\section{1 引言}

染料敏化太阳能电池采用环境友好材料, 具有 较高光电转换效率及易制备、低成本等优点, 使其最 有希望替代现有高成本硅基太阳能电池 ${ }^{[1]}$. 电池的关 键部件一一阳极中氧化物纳米晶膜承担着染料附着 体和电子传输通道的角色, 要求其具有较高的光散 射性能以提高光子捕获效率 ${ }^{[2]}$. 传统二氧化钛纳米晶 $\left(\mathrm{Nano}-\mathrm{TiO}_{2}\right)$ 膜的比表面积很大, 能吸附大量染料分子, 然而这种膜也存在如下影响电池光电性能的缺陷: 存在大面积光生电子与电解质离子复合的界面, 光 生电子传输过程可能被 nano- $\mathrm{TiO}_{2}$ 间大量晶界捕获进 而缩短扩散长度, 同时, 这类膜的光散射性能极弱 ${ }^{[3]}$. 因此, 需要采取有效措施来克服这些缺陷.

采用一维有序 nano- $\mathrm{TiO}_{2}$ 阵列如纳米棒、纳米线 和纳米管阵列能够大幅提高电子扩散长度至 100 $\mu \mathrm{m}^{[4,5]}$, 然而这些材料的比表面积较低、吸附染料很 少, 无法有效吸收太阳光子, 用这些材料制备的电池 光电性能比传统 nano- $\mathrm{TiO}_{2}$ 膜低得多 ${ }^{[6]}$. 近年来, 一 类新型的由氧化物纳米晶聚集体构成的膜引起了研 究人员的极大兴趣 ${ }^{[7]}$. 这些纳米晶聚集体的主要特征 是: 由高比表面积的纳米晶颗粒构成, 粒径能达到亚 微米或微米级 ${ }^{[8]}$. 这种特殊结构使其能够吸附大量染 料, 提高光谱吸收和散射性能, 而聚集体内纳米晶间 良好的连结性能也有利于光生电子传输, 聚集体间较 大的孔隙又有利于电解质渗透 ${ }^{[9]}$. 本文采用一种简单 的方法制备 nano- $\mathrm{TiO}_{2}$ 聚集体, 通过添加适量 $\mathrm{TiCl}_{4}$ 异丙醇溶液到传统 nano- $\mathrm{TiO}_{2}$ 浆料中, 可生成微米级 nano- $\mathrm{TiO}_{2}$ 聚集体. 含该二级结构光阳极的电池光电 性能有显著提高, 主要因为该结构有效克服了传统 nano- $\mathrm{TiO}_{2}$ 膜的缺陷, 同时又具有适宜电池光电转换 的特性. 


\section{2 实验部分}

\section{1 试剂}

试剂纯度均为分析纯, 购自国药集团化学试剂有 限公司, 不进行特殊处理直接使用. 钛酸四正丁酯、浓 硝酸、冰醋酸、 $\mathrm{TiCl}_{4}$ 、异丙醇、聚乙二醇(分子量为 20000)、 $\mathrm{NaI}$ 、四丁基碘化铵、 $\mathrm{I}_{2}$ 、乙腈、4-特丁基吡 啶. 导电玻璃(FTO, 方块电阻 $15 \Omega / \mathrm{sq}$ ) 购自日本 Nippon 玻璃公司, 用于制备光阳极 nano- $\mathrm{TiO}_{2}$ 膜. 敏 化染料 N719 (2-四丁铵-双(异硫氰基)双(2,2'-联吡啶 -4, $4^{\prime}$-二羧基)钌(II))购自澳大利亚 Dye sol 公司.

\subsection{Nano- $\mathrm{TiO}_{2}$ 浆料制备}

粒径为 10 20 nm 的 nano- $\mathrm{TiO}_{2}$ 颗粒合成方法如下: 首先向 $100 \mathrm{~mL}$ 去离子水中快速倒入 $10 \mathrm{~mL}$ 钛酸四正 丁酯, 剧烈搅拌 $2 \mathrm{~h}$ 生成白色沉淀. 经砂芯漏斗抽滤后, 用 $100 \mathrm{~mL}$ 去离子水洗涤沉淀 3 次, 将沉淀倒入 100 $\mathrm{mL} 0.1 \mathrm{~mol} / \mathrm{L}$ 硝酸水溶液中, 同时加入 $10 \mathrm{~mL}$ 冰醋酸, 混合均匀密封后在 $80{ }^{\circ} \mathrm{C}$ 下搅拌至完全溶解生成半透 明偏蓝色溶液. 将该溶液转移到水热反应金, $200^{\circ} \mathrm{C}$ 反 应 $12 \mathrm{~h}$ 生成乳白色浆液. 上述步骤重复多次以获得足 够量 nano- $\mathrm{TiO}_{2}$ 颗粒.

将乳白色浆液按 $50 \mathrm{~mL} /$ 份分为多份, 每份含 1.15 $\mathrm{g}$ nano- $\mathrm{TiO}_{2}$ 颗粒, 经 $12000 \mathrm{r} / \mathrm{min}$ 离心分离后倒去 35 $\mathrm{mL}$ 上层清夜, 向余下的浆液中添加 $0.3 \mathrm{~g}$ 聚乙二醇和 不同体积 $(0 、 0.5 、 1 、 1.5 、 2 、 3$ 和 $4 \mathrm{~mL}) 0.5 \mathrm{~mol} / \mathrm{L} \mathrm{TiCl}_{4}$ 异丙醇溶液. 将这些样品在 $100{ }^{\circ} \mathrm{C}$ 搅拌浓缩到 $10 \mathrm{~mL}$, 再加入 $10 \mathrm{~mL}$ 未离心处理的乳白色浆液, 搅拌均匀备 用. 获得的浆料按照 $\mathrm{TiCl}_{4}$ 异丙醇溶液添加体积标注 为 $\mathrm{TiCl}_{4}-N(N=0 、 0.5 、 1 、 1.5 、 2 、 3$ 和 4$)$ 浆料.

\section{3 器件制备}

首先将 $\mathrm{FTO}$ 浸在 $90^{\circ} \mathrm{C} \quad 0.05 \mathrm{~mol} / \mathrm{L} \mathrm{TiCl}$ 水溶液 中处理 $10 \mathrm{~min}$ 并在 $80^{\circ} \mathrm{C}$ 烘干. 分别用 $\mathrm{TiCl}_{4}-N(N=0$ 、 $0.5 、 1 、 1.5 、 2 、 3$ 和 4)浆料在处理过的 FTO 上采用 刮涂法制备 nano- $\mathrm{TiO}_{2}$ 膜. 这些膜经过 $450^{\circ} \mathrm{C}$ 烧结 0.5 $\mathrm{h}$ 并自然冷却到 $80^{\circ} \mathrm{C}$ 后, 浸入 $2.5 \times 10^{-4} \mathrm{~mol} / \mathrm{L} \mathrm{N} 719$ 无水乙醇溶液中 $24 \mathrm{~h}$ 形成染料敏化光阳极. 电池铂 对电极采用本研究组之前报道的热分解法制备 ${ }^{[10]}$. 将光阳极和对电极夹在一起, 两电极间填充液体电 解质(组分为 $0.4 \mathrm{~mol} / \mathrm{L} \mathrm{NaI} 、 0.1 \mathrm{~mol} / \mathrm{L}$ 四丁基碘化铵、 $0.5 \mathrm{~mol} / \mathrm{L} \mathrm{4}$-特丁基吡啶和 $0.05 \mathrm{~mol} / \mathrm{L} \mathrm{I}_{2}$ 的乙腈溶液).
用 $30 \mu \mathrm{m}$ 厚氰基丙烯酸双面胶初步封装电池, 再用 双酚 $\mathrm{A}$ 型环氧树脂进一步封装. 按所用浆料分别 将 nano- $\mathrm{TiO}_{2}$ 膜或光阳极标注为 $\mathrm{TiCl}_{4}-N(N=0 、 0.5$ 、 $1 、 1.5 、 2 、 3$ 和 4) nano- $\mathrm{TiO}_{2}$ 膜或光阳极, 将对应的 电池标注为 $\mathrm{TiCl}_{4}-N(N=0 、 0.5 、 1 、 1.5 、 2 、 3$ 和 4$)$ 电池.

\section{4 测试表征}

用场发射扫描电镜(FESEM, S-4800, 日立公司, 日本)观测 nano- $\mathrm{TiO}_{2}$ 膜形貌; 用 UV-vis 3100 光谱仪 (岛津公司, 日本)测试紫外可见吸收和散射光谱; 用 CHI660C 电化学工作站(CHI 仪器公司, 美国)测试电 化学阻抗谱(EIS); 采用本研究组之前报道的方法 ${ }^{[11]}$, 用 Zview 软件选适合电池特性的等效电路来拟合阻抗 数据 ${ }^{[12]}$. 通过测试电流-电压曲线获得电池光电性能 参数, 测试条件为 $\mathrm{AM} 1.5 \mathrm{G} 100 \mathrm{~mW} / \mathrm{cm}^{2}$, 采用 CHF-XM500 氙灯模拟太阳光源(北京畅拓仪器有限公 司), 用 CHI660C 电化学工作站记录数据. 所有电池样 品测试 3 次取平均值, 电池有效面积为 $0.125 \mathrm{~cm}^{2}(0.5$ $\mathrm{cm} \times 0.25 \mathrm{~cm})$. 采用 Newport IPCE 系统(Newport 仪器 公司, 美国)测试单色光光电转换效率(IPCE), 波段为 300 800 nm.

\section{3 结果与讨论}

图 1 为 $\mathrm{TiCl}_{4}-N(N=0 、 0.5 、 1 、 1.5 、 2 、 3$ 和 4) 浆料制备的 nano- $\mathrm{TiO}_{2}$ 膜表面 FESEM 图. 由图可见, 样品表面形貌存在明显区别. 例如, $\mathrm{TiCl}_{4}-0$ 膜为均匀 的介孔结构, 其他样品则出现了由不规则微米级球 形 nano- $\mathrm{TiO}_{2}$ 聚集体构成的二级结构. 同时还发现, 随着 $\mathrm{TiCl}_{4}$ 异丙醇溶液添加量的增加, 这些不规则 nano- $\mathrm{TiO}_{2}$ 聚集体的粒径逐渐减小, 均匀性逐步提高. 其原因如下: 添加到浆料中的 $\mathrm{TiCl}_{4}$ 覆盖在 nano- $\mathrm{TiO}_{2}$ 颗粒表面, 替换了部分表面稳定剂, 导致 nano- $\mathrm{TiO}_{2}$ 颗粒不稳定而形成聚集体; 随着 $\mathrm{TiCl}_{4}$ 异丙醇溶液添 加量的增加, $\mathrm{TiCl}_{4}$ 能较为均匀的分散在浆料中, 使 nano- $\mathrm{TiO}_{2}$ 聚集体数量变多, 粒径自然减小, 均匀性 也有所提高. 如图 $1(\mathrm{~d} \sim \mathrm{g})$ 所示, 含较高 $\mathrm{TiCl}_{4}$ 异丙醇 溶液添加量的样品表面变模糊, 主要是因为随着浆 料中 $\mathrm{TiCl}_{4}$ 量的增加, 其热分解生成的 $\mathrm{TiO}_{2}$ 颗粒数量 也增多, 对 nano- $\mathrm{TiO}_{2}$ 聚集体表面的覆盖率提高, 从 而使聚集体表面变模糊. 
图 2 是用 $\mathrm{TiCl}_{4}-0 、 \mathrm{TiCl}_{4}-1$ 和 $\mathrm{TiCl}_{4}-4$ 浆料制备的 nano- $\mathrm{TiO}_{2}$ 膜表面高倍率 FESEM 图. 由图可知, $\mathrm{TiCl}_{4}-0$ 膜由均匀分散的 nano- $\mathrm{TiO}_{2}$ 颗粒和纳米级孔洞 构成. $\mathrm{TiCl}_{4}-1$ 膜中出现了微米级 nano- $\mathrm{TiO}_{2}$ 聚集体, 这些聚集体也由均匀分散的 nano- $\mathrm{TiO}_{2}$ 颗粒和纳米级 孔洞构成, 与 $\mathrm{TiCl}_{4}-0$ 膜结构相似. 然而, $\mathrm{TiCl}_{4}-4$ 膜中 nano- $\mathrm{TiO}_{2}$ 聚集体结构变致密. 这些样品形貌的变化 主要由浆料中 $\mathrm{TiCl}_{4}$ 含量不同引起. 少量 $\mathrm{TiCl}_{4}$ 仅能降 低部分 nano- $\mathrm{TiO}_{2}$ 颗粒表面稳定性, 形成聚集体; 而
过量 $\mathrm{TiCl}_{4}$ 将覆盖在 nano- $\mathrm{TiO}_{2}$ 颗粒表面同时填充到 纳米级孔洞内, 经过热处理后, 生成的 $\mathrm{TiO}_{2}$ 颗粒将使 介孔结构消失 ${ }^{[13]}$.

图 3 是用 $\mathrm{TiCl}_{4}-0 、 \mathrm{TiCl}_{4}-1$ 和 $\mathrm{TiCl}_{4}-4$ 浆料制备的 nano- $\mathrm{TiO}_{2}$ 膜截面 FESEM 图. 由于采用一次刮涂法难 以制备较厚的 $\mathrm{TiCl}_{4}-0$ 膜, 同时为方便比较, 所有样品 膜厚度均固定为 $6 \mu \mathrm{m}$. 由图可知, $\mathrm{TiCl}_{4}-0$ 膜截面形貌 均匀, 另两个样品从正面和截面均可观测到二级结构. 同时也可看出, 这些 nano- $\mathrm{TiO}_{2}$ 聚集体间连结良好, 没
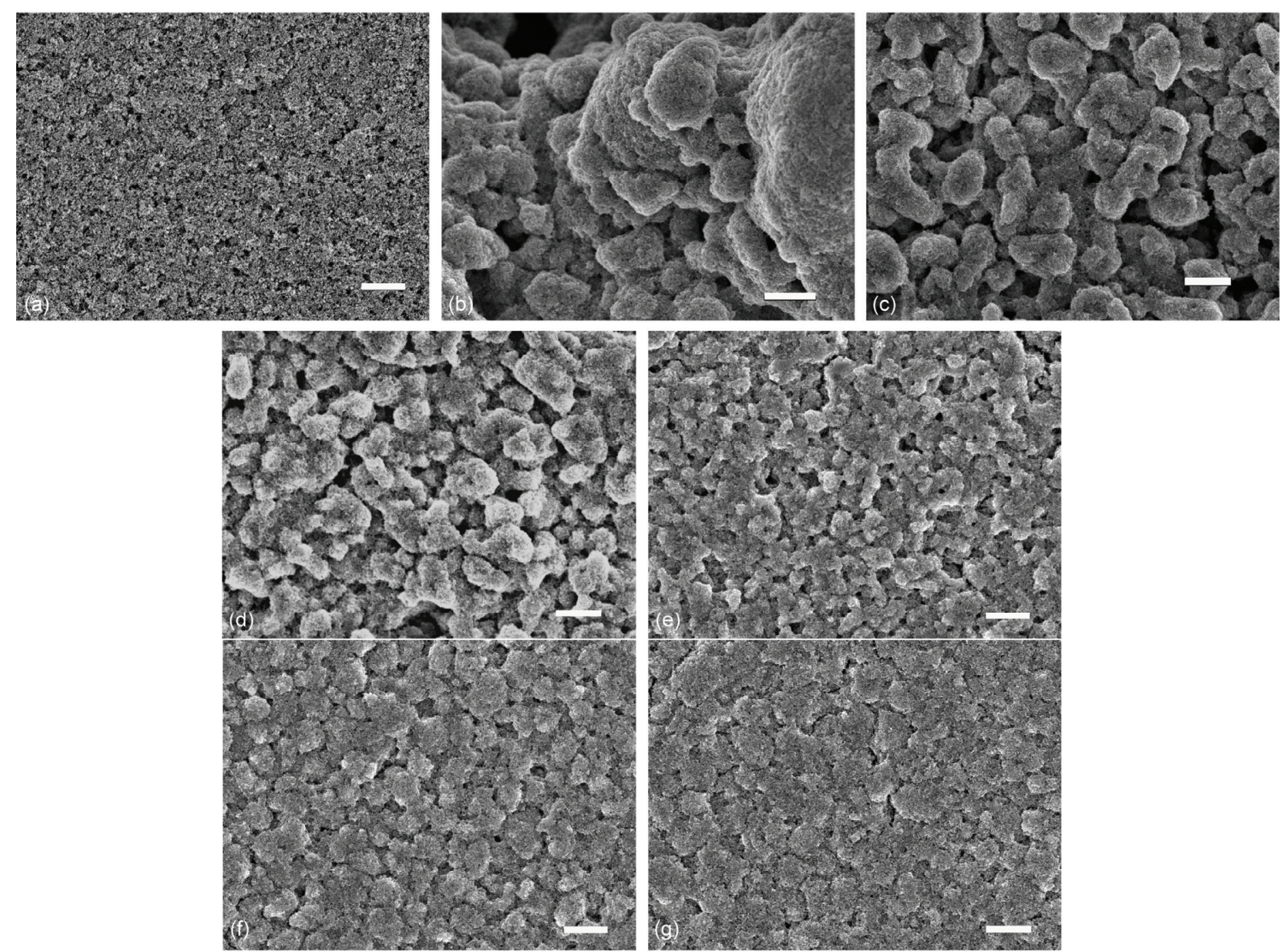

图 $1 \quad(\mathrm{a} \sim \mathrm{g})$ 由不同浆料 $\mathrm{TiCl}_{4}-N\left(N=0 、 0.5 、 1 、 1.5 、 2 、 3\right.$ 和 4)制备的 nano- $\mathrm{TiO}_{2}$ 膜表面 $\mathrm{FESEM}$ 图(标尺尺寸为 $\left.1 \mu \mathrm{m}\right)$
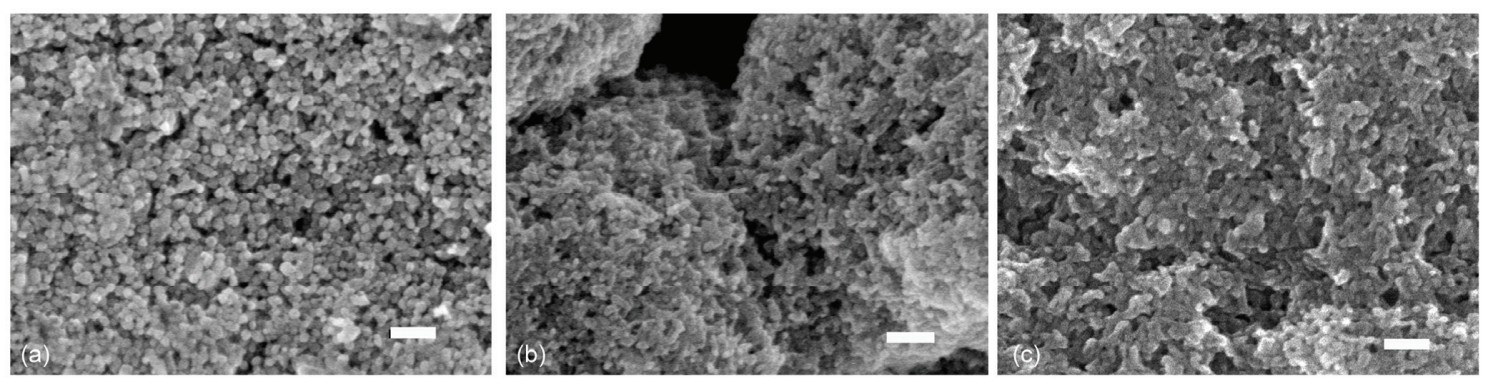

图 2 由浆料 $\mathrm{TiCl}_{4}-0$ (a)、 $\mathrm{TiCl}_{4}-1$ (b) 和 $\mathrm{TiCl}_{4}-4$ (c)制备的 nano- $\mathrm{TiO}_{2}$ 膜表面高倍率 $\mathrm{FESEM}$ 图(标尺尺寸为 $100 \mathrm{~nm}$ ) 

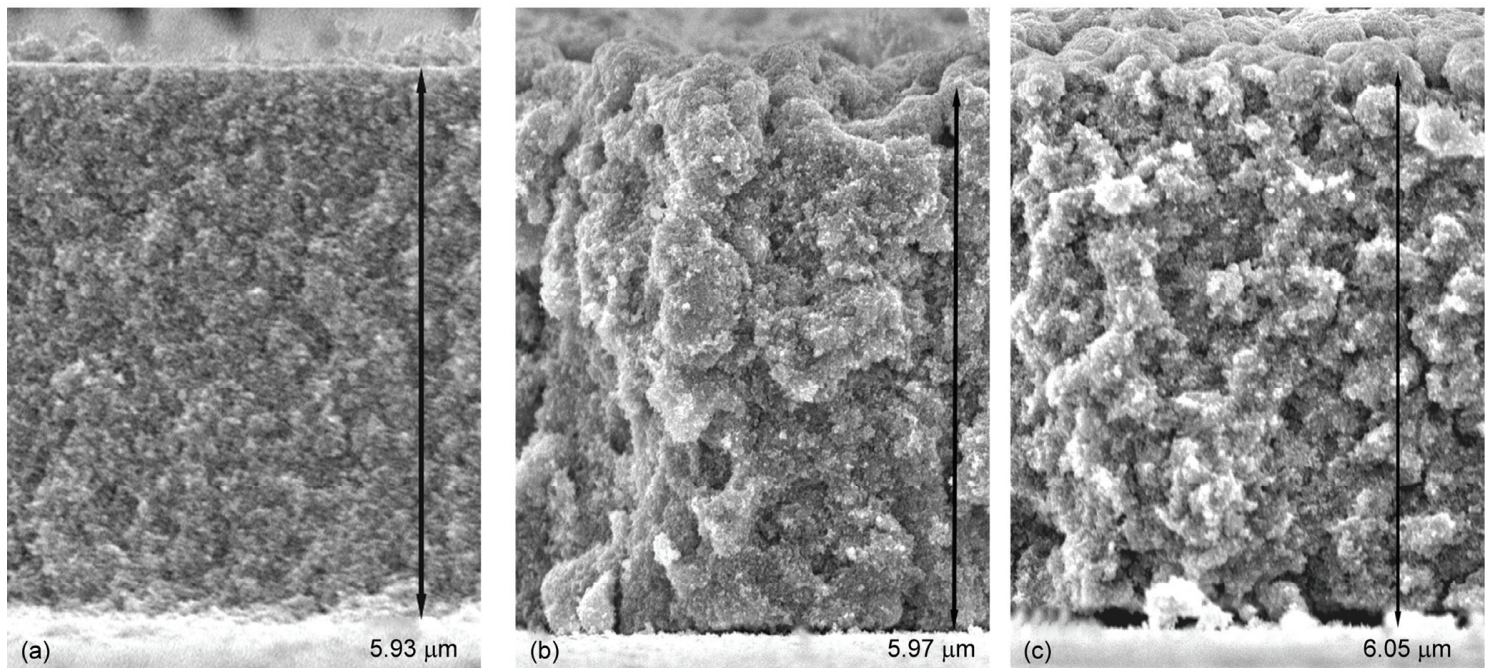

图 3 由浆料 $\mathrm{TiCl}_{4}-0(\mathrm{a}) 、 \mathrm{TiCl}_{4}-1$ (b) 和 $\mathrm{TiCl}_{4}-4$ (c)制备的 nano- $\mathrm{TiO}_{2}$ 膜截面 FESEM 图

\section{有形成大孔洞.}

光散射性能是影响光阳极光子捕获能力的重要因 素. Nano- $\mathrm{TiO}_{2}$ 膜紫外可见散射光谱如图 4(a)所示, 由 图可见, 用添加 $\mathrm{TiCl}_{4}$ 异丙醇溶液的浆料制备的膜具 有良好光散射性能, 光散射率在 400 800 $\mathrm{nm}$ 光谱波段 均显著高于传统 nano- $\mathrm{TiO}_{2}$ 膜, 主要因为这些膜的二 级结构能有效散射太阳光子 ${ }^{[14]}$. 从图中也可看到, $\mathrm{TiCl}_{4}-0.5 、 \mathrm{TiCl}_{4}-1 、 \mathrm{TiCl}_{4}-1.5$ 和 $\mathrm{TiCl}_{4}-2$ 膜的光散射率 相近, 没有明显区别, 这是因为膜内 nano- $\mathrm{TiO}_{2}$ 聚集体 粒径足够大同时具有相似的二级结构. 采用 $\mathrm{TiCl}_{4}$ 异 丙醇溶液添加量较高的浆料制备的膜如 $\mathrm{TiCl}_{4}-3$ 和 $\mathrm{TiCl}_{4}-4$ 膜, 光散射率还可进一步升高, 这源于这些膜 具有较为疏松的结构(图 1).

图 4(b)为染料敏化后 nano- $\mathrm{TiO}_{2}$ 膜的紫外可见吸 收光谱. 在 500 550 nm 最大吸收波段, 用添加 $\mathrm{TiCl}_{4}$ 异丙醇溶液的浆料制备的膜吸收强度随着添加量的 增加逐渐提高. 当添加量达到 $2 \mathrm{~mL}$ 时, 吸收强度达到 最大值, 之后继续增大添加量, 吸收强度反而下降. 同时, 这些膜具有更宽的光谱吸收波段, 能延伸到染 料吸收很弱的长波段区域 $(>600 \mathrm{~nm}$ ). 用 $1 \mathrm{mmol} / \mathrm{L}$ $\mathrm{NaOH}$ 乙醇溶液将膜上染料脱附并测其吸收强度, 可 计算出膜的染料吸附量, 结果列于表 1 . 从表中数据 可知, 用添加 $\mathrm{TiCl}_{4}$ 异丙醇溶液的浆料制备的膜染料 吸附量均高于传统 nano- $\mathrm{TiO}_{2}$ 膜, 最大吸附量能达到 $0.477 \times 10^{-7} \mathrm{~mol} / \mathrm{cm}^{2}\left(\mathrm{TiCl}_{4}-2\right.$ 膜 $)$, 比 $\mathrm{TiCl}_{4}-0$ 膜的吸附 量 $\left(0.412 \times 10^{-7} \mathrm{~mol} / \mathrm{cm}^{2}\right)$ 提高了 $15.78 \%$.
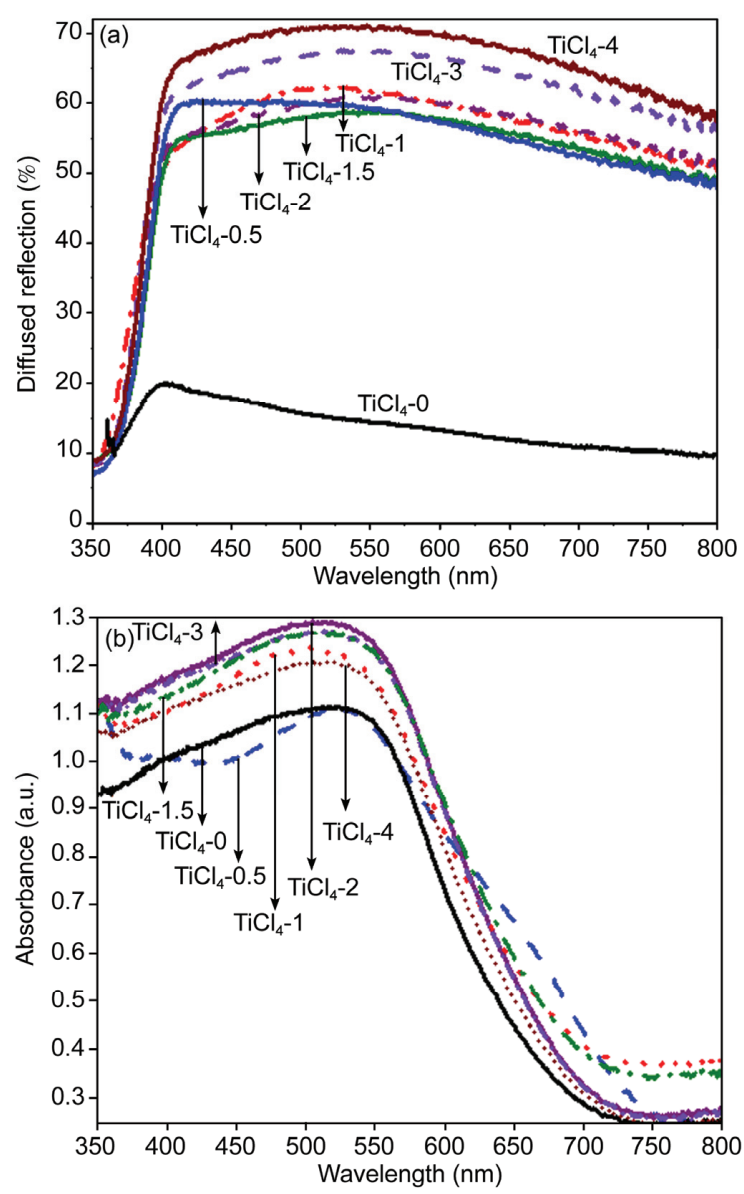

图 $4 \mathrm{TiCl}_{4}-N(N=0 、 0.5 、 1 、 1.5 、 2 、 3 、 4)$ nano- $\mathrm{TiO}_{2}$ 膜 的紫外可见散射光谱(a)和染料敏化后 nano- $\mathrm{TiO}_{2}$ 膜的紫外可 见吸收光谱(b) 
表 1 由图 6 获得的 $\mathrm{TiCl}_{4}-N(N=0 、 0.5 、 1 、 1.5 、 2 、 3$ 和 4$)$ 电池的光电性能参数

\begin{tabular}{lccccc}
\hline DSC & Dye conc. $\left(\times 10^{-7} \mathrm{~mol} / \mathrm{cm}^{2}\right)$ & $I_{\mathrm{sc}}\left(\mathrm{mA} / \mathrm{cm}^{2}\right)$ & $V_{\text {oc }}(\mathrm{V})$ & $F F$ & Eff $(\%)$ \\
\hline $\mathrm{TiCl}_{4}-0$ & 0.412 & 9.72 & 0.727 & 0.712 & 5.03 \\
$\mathrm{TiCl}_{4}-0.5$ & 0.411 & 12.10 & 0.718 & 0.711 & 6.18 \\
$\mathrm{TiCl}_{4}-1$ & 0.457 & 13.90 & 0.714 & 0.736 & 7.30 \\
$\mathrm{TiCl}_{4}-1.5$ & 0.471 & 13.30 & 0.719 & 0.694 & 6.64 \\
$\mathrm{TiCl}_{4}-2$ & 0.477 & 11.66 & 0.706 & 0.729 & 6.00 \\
$\mathrm{TiCl}_{4}-3$ & 0.469 & 8.50 & 0.687 & 0.721 & 4.21 \\
$\mathrm{TiCl}_{4}-4$ & 0.446 & 7.82 & 0.678 & 0.771 & 4.09 \\
\hline
\end{tabular}

染料敏化太阳能电池的 IPCE 可由如下 3 个参数 决定: $\operatorname{IPCE}(\lambda)=\eta_{\mathrm{abs}}(\lambda) \times \eta_{\mathrm{inj}}(\lambda) \times \eta_{\mathrm{col}}(\lambda)$, 其中 $\eta_{\mathrm{abs}}$ 是 染料对光的吸收率, $\eta_{\mathrm{inj}}$ 和 $\eta_{\mathrm{col}}$ 是光生电子注入和收集 效率 ${ }^{[15]} . \mathrm{TiCl}_{4}-N(N=0 、 0.5 、 1 、 1.5 、 2 、 3$ 和 4$)$ 电池 的 IPCE 曲线如图 5 所示. 从图可知, $\mathrm{TiCl}_{4}-N(N=$ $0.5 、 1 、 1.5$ 和 2) 电池的 IPCE 均高于 $\mathrm{TiCl}_{4}-0$ 电池. 从
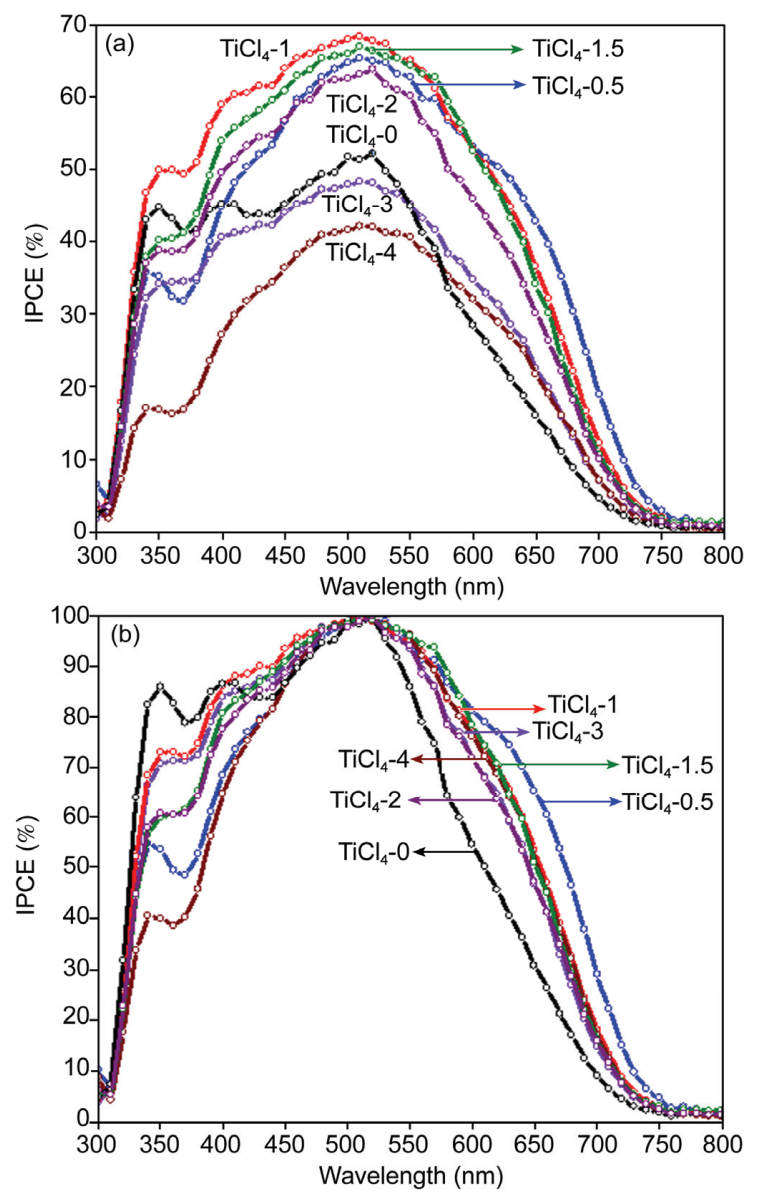

图 $5 \mathrm{TiCl}_{4}-N(N=0 、 0.5 、 1 、 1.5 、 2 、 3$ 和 4$)$ 电池 IPCE 曲 线(a)及归一化后 IPCE 曲线(b)
IPCE 关系式可知, 在短波段区(300 550 nm), IPCE 的 提高归因于染料吸附量的增加(图 4(b)); 而在长波段 区(550 750 nm), N719 染料对该波段太阳光的吸收较 弱, 所以 IPCE 的增加来源于光阳极散射率的提高. 将 IPCE 数据进行归一化处理, 能更清楚看出这种变 化趋势 ${ }^{[7]}$. 从图 5(b) 可知, $\mathrm{TiCl}_{4}-N(N=0.5 、 1 、 1.5 、 2$ 、 3 和 4) 电池在 550 750 nm 长波段区具有较高 IPCE, 主要由于 $\mathrm{TiCl}_{4}-N(N=0.5 、 1 、 1.5 、 2 、 3$ 和 4)膜具有 良好的光散射性能(图 4(a)). 同时可以观察到, 虽然 $\mathrm{TiCl}_{4}-3$ 和 $\mathrm{TiCl}_{4}-4$ 膜具有很高的光散射率和吸收率 (图 4), 但 $\mathrm{TiCl}_{4}-3$ 和 $\mathrm{TiCl}_{4}-4$ 电池的 IPCE 反而低于 $\mathrm{TiCl}_{4}-0$ 电池. 由于 IPCE 由 $\eta_{\mathrm{abs}} 、 \eta_{\mathrm{inj}}$ 和 $\eta_{\mathrm{col}} 3$ 个参数共 同决定, 因此, 除受 $\eta_{\mathrm{abs}}$ 影响外, 还可能由 $\eta_{\mathrm{inj}}$ 和/或 $\eta_{\mathrm{col}}$ 决定. 后面将通过 EIS 数据来分析这两个参数的 影响.

图 6 为 $\mathrm{TiCl}_{4}-N(N=0 、 0.5 、 1 、 1.5 、 2 、 3$ 和 4) 电池的电流-电压曲线, 其光电性能参数列于表 1 . 由 数据可知, $\mathrm{TiCl}_{4}-N(N=0.5 、 1 、 1.5$ 和 2$)$ 电池光电转

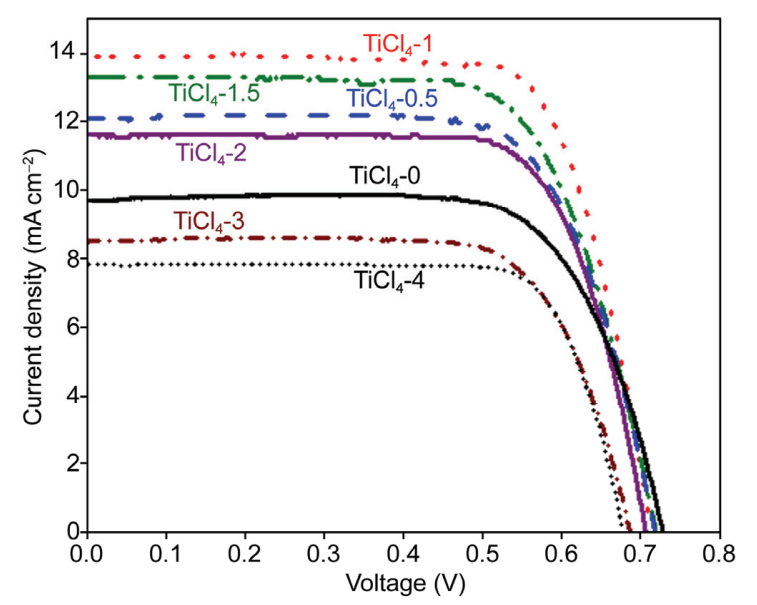

图 $6 \mathrm{TiCl}_{4}-N(N=0 、 0.5 、 1 、 1.5 、 2 、 3$ 和 4$)$ 电池电流-电 压曲线, 光阳极 nano- $\mathrm{TiO}_{2}$ 膜厚为 $6 \mu \mathrm{m}$ 
换效率 $(\mathrm{PCE})$ 均高于 $\mathrm{TiCl}_{4}-0$ 电池, 主要由于这些电池 短路电流 $\left(I_{\mathrm{sc}}\right)$ 较高. 然而, 较低的 $I_{\mathrm{sc}}$ 和开路电压 $\left(V_{\mathrm{oc}}\right)$ 使得 $\mathrm{TiCl}_{4}-3$ 和 $\mathrm{TiCl}_{4}-4$ 电池 PCE 较低. 各电池 $I_{\mathrm{sc}}$ 的 变化趋势与 IPCE 变化趋势一致, 由光阳极光子捕获 效率决定 ${ }^{[16]}$. 但是, 由于部分电池光电性能变化趋势 与其光阳极光子捕获效率变化趋势不一致, 因此, 这 不是决定电池光电性能的唯一因素. 例如, $\mathrm{TiCl}_{4}-3$ 和 $\mathrm{TiCl}_{4}-4$ 光阳极的光子捕获效率均高于 $\mathrm{TiCl}_{4}-0$ 光阳极, 但这两个电池的 $I_{\mathrm{sc}}$ 并不高; $\mathrm{TiCl}_{4}-1$ 电池具有最高光 电转换效率, 但 $\mathrm{TiCl}_{4}-1$ 光阳极在这些样品中光子捕 获效率并非最高. 这些样品中具有最佳光电性能的 $\mathrm{TiCl}_{4}-1$ 电池的 PCE 为 $7.30 \%$, 比采用相同厚度传统 nano- $\mathrm{TiO}_{2}$ 膜 $(6 \mu \mathrm{m})$ 的电池 PCE 高 $(5.03 \%)$. 通过进一 步优化光阳极厚度, $\mathrm{TiCl}_{4}-1$ 电池 $\mathrm{PCE}$ 还可以进一步 提高.

除光子捕获效率外, 光阳极电子传输性能也是 影响电池光电性能的重要因素. 通过 EIS 测试, 可获 得电子传输性能相关参数. 图 7(a) 为各电池 EIS 谱图, 用传输线模型(图 7(b)) 来拟合电子传输过程, 该模型 将 nano- $\mathrm{TiO}_{2}$ 膜看作完整的交联网络. 决定电池性能 的主要阻抗参数如电荷传输电阻 $\left(R_{\mathrm{tr}}\right)$ 、界面电荷复合 电阻 $\left(R_{\mathrm{r}}\right)$ 、电容 $\left(C_{\mathrm{u}}\right)$ 可由如下关系式求得: $R_{\mathrm{tr}}=r_{\mathrm{tr}} L, R_{\mathrm{r}}$ $=r_{\mathrm{ct}} / L$ 和 $C_{\mathrm{u}}=c_{\mathrm{u}} L$, 其中 $L$ 为 nano- $\mathrm{TiO}_{2}$ 膜厚度. 此外, 可同时求得电子寿命 $\tau_{n}\left(\tau_{n}=R_{\mathrm{r}} C_{\mathrm{u}}\right)$ ，电子有效扩散长 度 $L_{n}\left(L_{n}=L\left(R_{\mathrm{r}} / R_{\mathrm{tr}}\right)^{0.5}\right)$ 和电子收集效率 $\eta_{\mathrm{col}}\left(\eta_{\mathrm{col}}=\right.$

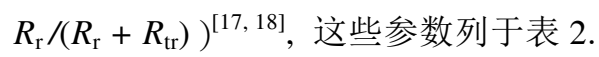

从表 2 数据可知, 各电池 $L_{n}$ 均大于 $6 \mu \mathrm{m}$, 说明 其具有良好电子传输性能. $\mathrm{TiCl}_{4}-3$ 和 $\mathrm{TiCl}_{4}-4$ 电池 $\tau_{n}$ 较低, 使这两个电池 $\eta_{\text {inj }}$ 较低, 同时这两个电池 $\eta_{\mathrm{col}}$ 也 低于其他电池, 因此, 其 PCE 较低. 从图 6 数据也可 以看出, $\mathrm{TiCl}_{4}-3$ 和 $\mathrm{TiCl}_{4}-4$ 电池 $V_{\mathrm{oc}}$ 也低于其他电池, 由于两电池 $R_{\mathrm{r}}$ 较低, 其暗反应较大, 较为严重的复合 反应是导致其 $V_{\mathrm{oc}}$ 较低的主要原因 ${ }^{[19]}$.

\section{4 结论}

往传统 nano- $\mathrm{TiO}_{2}$ 浆料中添加少量 $\mathrm{TiCl}_{4}$ 异丙醇 溶液, 能原位生成微米级 nano- $\mathrm{TiO}_{2}$ 聚集体. 采用这 种简单方法, 可制备出一种新型的具有二级结构的 光阳极. 相关性能测试表明, 该二级结构能有效提高光 阳极光谱吸收和散射性能及电子传输和收集效率. 基 于这种新型光阳极的电池光电转换效率显著高于含 传统 nano- $\mathrm{TiO}_{2}$ 膜光阳极的电池. 通过优化 $\mathrm{TiCl}_{4}$ 异丙 醇溶液添加量, 具有最佳光电性能的 $\mathrm{TiCl}_{4}-1$ 电池光 电转换效率能达到 $7.30 \%$, 明显高于相同厚度光阳极 $(6 \mu \mathrm{m})$ 的 $\mathrm{TiCl}_{4}-0$ 电池 $(5.03 \%)$. 优化 $\mathrm{TiCl}_{4}-1$ 电池光阳 极厚度, 光电转换效率可进一步提高. 因此, 这是一 种制备高效染料敏化太阳能电池简单且有效的方法.

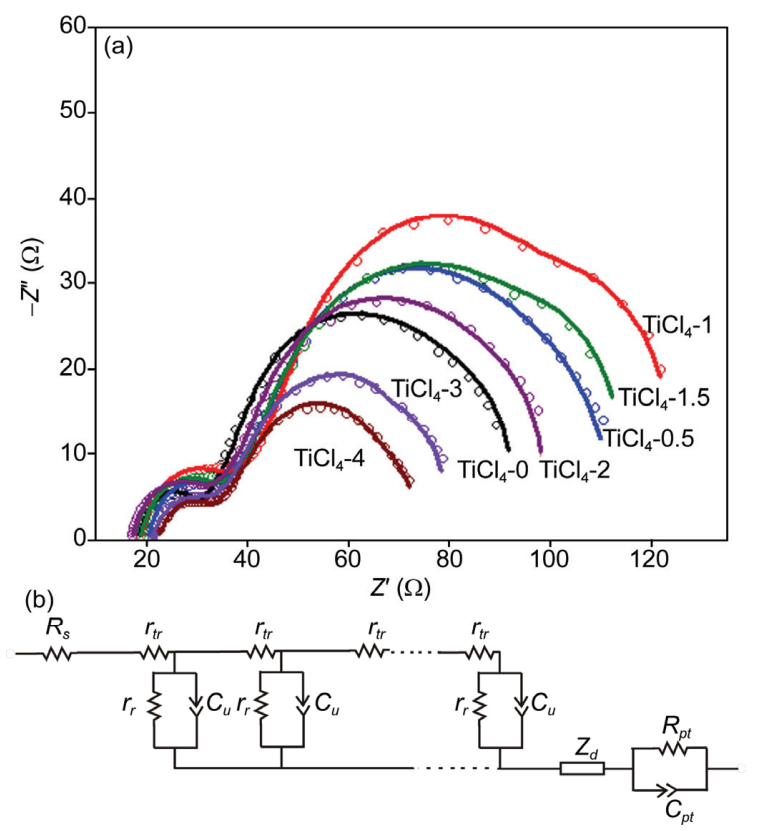

图 $7 \mathrm{TiCl}_{4}-N(N=0 、 0.5 、 1 、 1.5 、 2 、 3$ 和 4$)$ 电池的阻抗图 (施加 $0.7 \mathrm{~V}$ 偏压, 在暗态下测试) (a) 和拟合等效电路图(点为 实测数据, 线为按等效电路拟合的结果) (b)

表 2 由图 7 获得的 $\mathrm{TiCl}_{4}-N(N=0 、 0.5 、 1 、 1.5 、 2 、 3$ 和 4)电池阻抗拟合参数

\begin{tabular}{lcccccc}
\hline DSC & $R_{\mathrm{tr}}(\Omega)$ & $R_{\mathrm{r}}(\Omega)$ & $C_{\mathrm{u}}(\mu \mathrm{F})$ & $\eta_{\mathrm{col}}(\%)$ & 85.21 & $L_{n}(\mu \mathrm{m})$ \\
\hline $\mathrm{TiCl}_{4}-0$ & 13.89 & 80.03 & 878.21 & 876.49 & 86.02 & 14.40 \\
$\mathrm{TiCl}_{4}-0.5$ & 13.51 & 83.15 & 549.54 & 91.04 & 14.88 \\
$\mathrm{TiCl}_{4}-1$ & 14.33 & 145.65 & 599.64 & 89.42 & 19.12 \\
$\mathrm{TiCl}_{4}-1.5$ & 14.92 & 126.12 & 875.03 & 85.91 & 17.44 \\
$\mathrm{TiCl}_{4}-2$ & 12.52 & 76.35 & 63.52 & 261.57 & 85.09 & 14.82 \\
$\mathrm{TiCl}_{4}-3$ & 11.13 & 48.74 & 296.43 & 82.12 & 14.34 \\
$\mathrm{TiCl}_{4}-4$ & 10.61 & & & 12.85 & 1 \\
\hline
\end{tabular}


本工作得到国家自然科学基金(U1205112，51002053)、教育部科技重点项目(212206)、福建省高校杰出青年 研究人才项目、福建省新世纪优秀人才支持计划项目和华侨大学中青年教师提升资助计划(ZQN-YX102)资 助, 特此一并致谢.

\section{参考文献}

1 O'Regan B, Grätzel M. A low-cost, high-efficiency solar cell based on dye-sensitized colloidal TiO 2 films. Nature, 1991, 353: 737-740

2 Lan Z, Wu JH, Lin JM, Huang ML. Controllable hydrothermal synthesis of nanocrystal TiO $\mathrm{T}_{2}$ particles and their use in dye-sensitized solar cells. Sci China Chem, 2012, 55: 1308-1313

3 Phadke S, Pasquier AD, Bimie DP. Enhanced electron transport through template-derived pore channels in dye-sensitized solar cells. J Phys Chem C, 2011, 115: 18342-18347

4 Xing BT, Wang CR, Luo JY, Chen BX, Zhou BX, Zhu ZY. Highly-ordered dye-sensitized TiO ${ }_{2}$ nanotube arrays film used for improving photoelectrochemical electrodes. Sci China Chem, 2013, 56: 101-105

5 Yen YC, Ko WY, Chen JZ, Lin KJ. Enhancing the performance of dye-sensitized solar cells based on TiO ${ }_{2}$ nanotube/nanoparticle composite photoanodes. Electrochimi Acta, 2013, 105: 142-148

6 Liao JY, Lei BX, Chem HY, Kuang DB, Su CY. Oriented hierarchical single crystalline anatase TiO $\mathrm{T}_{2}$ nanowire arrays on Ti-foil substrate for efficient flexible dye-sensitzed solar cells. Energy Environ Sci, 2012, 5: 5750-5757

7 Sauvage F, Chen D, Comte P, Huang F, Heiniger L, Cheng YB, Caruso RA, Grätzel M. Dye-sensitized solar cells employing a single film of mesoporous $\mathrm{TiO}_{2}$ beads achieve power conversion efficiencies over 10\%. ACS Nano, 2010, 4: 4420-4425

8 Du J, Lai XY, Halpert JE, Yang Y, Wang D. Formation of efficient dye-sensitized solar cells by introducing an interfacial layer of hierarchically ordered macro-mesoporous $\mathrm{TiO}_{2}$ film. Sci China Chem, 2011, 54: 930-935

9 Zhang Q, Park K, Xi J, Myers D, Cao G. Recent progress in dye-sensitized solar cells using nanocrystallite aggregates. Adv Energy Mater, 2011, 1: 988-1001

10 Lan Z, Wu J, Lin J, Huang M. Morphology controllabe fabrication of Pt counter electrodes for highly efficient dye-sensitized solar cells. J Mater Chem, 2012, 22: 3948-3954

11 Lan Z, Wu J, Lin J, Huang M. A high efficiency dye-sensitized solar cell with nano-TiO ${ }_{2}$ secondary structure in the photoanode. Funct Mater Lett, 2013, 2: 1350014

12 Wang Q, Moser JE, Grätzel M. Electrochemical impedance spectroscopic analysis of dye-sensitized solar cells. J Phys Chem B, 2005, 109: $14945-14953$

13 Lee SW, Ahn KS, Zhu K, Neale NR, Frank AJ. Effects of $\mathrm{TiCl}_{4}$ treatment of nanoporous $\mathrm{TiO}_{2}$ films on morphology, light harvesting, and charge-carrier dynamics in dye-sensitized solar cells. J Phys Chem C, 2012, 116: 21285-21290

14 Huang F, Chen D, Zhang XL, Caruso RA, Cheng YB. Dual-function scattering layer of submicrometer-sized mesoporous TiO ${ }_{2}$ beads for high-efficiency dye-sensitized solar cells. Adv Funct Mater, 2010, 20: 1301-1305

15 Grätzel M. Solar energy conversion by dye-sensitized photovoltaic cells. Inorg Chem, 2005, 44: 6841-6851

16 Wang ZS, Cui Y, Hara K, Dan-oh Y, Kasada C, Shinpo A. A high-light-harvesting-efficiency coumarin dye for stable dye-sensitized solar cells. Adv Mater, 2007, 19: 1138-1141

17 Wang KP, Teng H. Zinc-doping in $\mathrm{TiO}_{2}$ films to enhance electron transport in dye-sensitized solar cells under low-intensity illumination. Phys Chem Chem Phys, 2009, 11: 9489-9496

18 Bisquert J, Garcia-Belmonte G, Fabregat-Santiago F, Ferriols NS, Bogdanoff P, Pereira EC. Doubling exponent models for the analysis of porous film electrodes by impedance. Relaxation of $\mathrm{TiO}_{2}$ nanoporous in aqueous solution. J Phys Chem B, 2000, 104: 2287- 2298

19 Huang SY, Schlichthorl G, Nozik AJ, Grätzel M, Frank AJ. Charge recombination in dye-sensitized nanocrystalline TiO ${ }_{2}$ solar cells. J Phys Chem B, 1997, 101: 2576-2582 


\title{
$\mathrm{TiCl}_{4}$ assisted formation of nano- $\mathrm{TiO}_{2}$ secondary structure in photoactive electrodes for high efficiency dye-sensitized solar cells
}

\author{
LAN Zhang*, WU JiHuai*, LIN JianMing, HUANG MiaoLiang \\ Engineering Research Center of Environment-Friendly Functional Materials, Ministry of Education; Key Laboratory of Functional \\ Materials for Fujian Higher Education; Institute of Materials Physical Chemistry, Huaqiao University, Xiamen 361021, China \\ *Corresponding authors (email: lanzhang@hqu.edu.cn; jhwu@hqu.edu.cn)
}

\begin{abstract}
A new kind of photoactive electrodes with nanocrystalline $\mathrm{TiO}_{2}$ (nano- $\mathrm{TiO}_{2}$ ) secondary structure is successfully prepared via a simple method of adding suitable amount of $\mathrm{TiCl}_{4}$ 2-propanol solution in conventional nano- $\mathrm{TiO}_{2}$ paste to form micro-sized nano- $\mathrm{TiO}_{2}$ aggregates. This special structure benefits improved optical absorption, increased light scattering ability, enhanced electron transport and collection efficiency. Dye-sensitized solar cells (DSCs) based on these photoactive electrodes show obviously improved performance. The power conversion efficiency of the cells can increase from $5.03 \%$ to a higher value of $7.30 \%$ by substituting $6 \mu \mathrm{m}$ conventional nano-TiO ${ }_{2}$ thin film with the same thickness of as-prepared nano- $\mathrm{TiO}_{2}$ aggregates film in the photoactive electrodes. A higher power conversion efficiency of the cell can be obtained by further increasing the thickness of the nano- $\mathrm{TiO}_{2}$ aggregates film.
\end{abstract}

Keywords: dye-sensitized solar cell, photoactive electrode, secondary structure, titanium tetrachloride additive 